\title{
Technical note: Validation of an automated in-line milk progesterone analysis system to diagnose pregnancy in dairy cattle
}

\author{
T. C. Bruinjé ${ }^{1}$ and D. J. Ambrose $e^{1,2 *}$ \\ ${ }^{1}$ Department of Agricultural, Food and Nutritional Science, University of Alberta, Edmonton, AB, Canada, T6G 2P5 \\ ${ }^{2}$ Livestock Research and Extension Branch, Alberta Agriculture and Forestry, Edmonton, AB, Canada, T6H 5T6
}

\begin{abstract}
The in-line milk analysis system (IMAS) is an automated biosensor technology that samples and quantifies milk progesterone concentrations $(\mathrm{P} 4 \mathrm{c})$ at frequent intervals starting early postpartum until pregnancy. The objective was to validate the use of pregnancy notifications (PregN) generated by an IMAS based on P4c profiles after artificial insemination (AI) to determine pregnancy and nonpregnancy status in dairy cows. Records of 1,821 AI events from 715 Holstein cows that had milk P4c $(\mathrm{ng} / \mathrm{mL})$ measured every $2.2 \pm 1.9 \mathrm{~d}$ (mean \pm standard deviation) between $24.5 \pm 8.2$ and $173.4 \pm 49.3 \mathrm{~d}$ in milk through a real-time IMAS (Herd Navigator, DeLaval International, Tumba, Sweden) were evaluated. Based on variations in adjusted milk $\mathrm{P} 4 \mathrm{c}$ ( $<$ vs. $\geq$ the $5.0 \mathrm{ng} / \mathrm{mL}$ threshold), the system determined the sampling frequency, onset and cessation of luteal phases, and pregnancy. If a luteal phase initiated (P4c increased to $\geq 5.0 \mathrm{ng} / \mathrm{mL}$ ) after $\mathrm{AI}$ and remained uninterrupted, a PregN was generated starting at (mean \pm standard deviation) $31.0 \pm 4.3 \mathrm{~d}$ until $53.4 \pm 7.9 \mathrm{~d}$ after AI, when sampling stopped, unless a decline in $\mathrm{P} 4 \mathrm{c}$ (to $<5.0 \mathrm{ng} / \mathrm{mL}$ ) occurred indicating nonpregnancy and imminent estrus. The assessment of IMAS PregN at 4 weekly intervals was tested, and a confirmed calving occurrence between 262 and $296 \mathrm{~d}$ after AI, with no other subsequent AI recorded, was the gold standard for pregnancy. In total, $14.1(256 / 1,821)$, $41.0(746 / 1,821)$, and $50.7 \%(924 / 1,821)$ of AI events were followed by a decline in P4c before 19, 23, and 30 $\mathrm{d}$ after AI, respectively. Frequency of the last 3 sampling events preceding $\mathrm{P} 4 \mathrm{c}$ decline was greater if $\mathrm{P} 4 \mathrm{c}$ decline occurred between 18 and $25 \mathrm{~d}$ after AI $(1.4 \pm 0.5$ samples per day) compared with before 17 or beyond 26 $\mathrm{d}$ after AI (1.0 \pm 0.5 samples per day). At $30 \pm 3(27$ to 33$)$ d after AI, PregN occurred in $46.8 \%(853 / 1,821)$ of AI events, of which $15.2 \%(130 / 853)$ had a decline in
\end{abstract}

Received September 14, 2018

Accepted November 20, 2018.

*Corresponding author: divakar.ambrose@gov.ab.ca
P4c between 30 and $55 \mathrm{~d}$ after $\mathrm{AI}$ and $17.1 \%(146 / 853)$ was later confirmed nonpregnant based on the gold standard. A total of $40.7 \%(742 / 1,821)$ of AI events was confirmed pregnant by the gold standard, which was no different than the proportion of PregN at $51 \pm 3$ (48 to $54)$ d $(40.9 \% ; 744 / 1,821)$. At any time point between 27 and $54 \mathrm{~d}$ after AI, sensitivity and negative predictive values for PregN were greater than 95.0 and $96.0 \%$, respectively, whereas specificity values were less than $90.0 \%$ for PregN before $40 \mathrm{~d}$ but greater than $94.0 \%$ for PregN beyond $41 \mathrm{~d}$ after AI. In conclusion, IMAS is able to diagnose pregnancy based on $\mathrm{P} 4 \mathrm{c}$ profiles with high precision and determine early nonpregnancy based on the spontaneous cessation of the luteal phase. However, for accuracy greater than 95.0\%, pregnancy declaration based on IMAS notifications alone should occur no earlier than $41 \mathrm{~d}$ after AI.

Key words: biosensor, dairy cow, pregnancy test, reproductive management

\section{Technical Note}

The accurate diagnosis of pregnancy or nonpregnancy at the earliest opportunity after AI is critical for the reproductive efficiency of dairy operations. A direct pregnancy diagnosis method such as transrectal ultrasonography can be accurately performed as early as $29 \mathrm{~d}$ after AI (Romano et al., 2006), whereas indirect methods such as pregnancy-associated glycoprotein measured in milk or blood are accurate when performed 28 d after AI (Mayo et al., 2016). Diagnosis of nonpregnancy is possible even earlier by Doppler ultrasonography (20 d; Siqueira et al., 2013) and progesterone measurement (25 d; Wilsdorf et al., 2016). However, such methods have poor true positive rates for confirming pregnancy (Siqueira et al., 2013: 53.7\%; Wilsdorf et al., 2016: 76.0\%) because of the high incidence of early pregnancy losses (Santos et al., 2004; Ricci et al., 2017), resulting in a high proportion of false positives necessitating a subsequent re-examination to confirm pregnancy. The aforementioned methods require considerable animal handling, labor, time, and technical 
inputs. Besides, laboratory tests are often not on farm and pregnancy or nonpregnancy determination may require up to several days. Therefore, for a pregnancy diagnosis to be effective, testing should start early after $\mathrm{AI}$ and occur frequently to identify nonpregnant cows in a timely manner until the risk of pregnancy losses wanes (Giordano et al., 2013; Fricke et al., 2016).

In this regard, a fully automated in-line milk analysis system (IMAS; Herd Navigator, DeLaval International, Tumba, Sweden) that samples and immediately quantifies milk progesterone concentrations $(\mathbf{P} 4 \mathbf{c})$ at frequent intervals in every eligible cow in the herd, has been in use in some Canadian herds since 2012. For the purpose of monitoring spontaneous ovarian activity, the IMAS biomodel starts sampling milk at approximately 3 wk postpartum and adjusts the sampling frequency according to the stage of the estrous cycle (Friggens and Chagunda, 2005). The main features of the IMAS for reproductive management include monitoring of resumption of postpartum luteal activity and subsequent luteal phases, declaring imminent estrus based on cessation of a luteal phase, and estimating early nonpregnancy or pregnancy status, all based on P4c profiles (DeLaval International, 2011; Saint-Dizier and Chastant-Maillard, 2012; Bruinjé et al., 2019). If determined accurate, the IMAS can be used as an automated diagnostic tool for pregnancy that includes identification of nonpregnant cows in a timely manner with no animal handling. Therefore, the objective of the present study was to validate the use of pregnancy notification (PregN) generated by the IMAS to determine pregnancy status in dairy cows.

Records of AI $(\mathrm{n}=1,821)$ from 811 lactations (365 primiparous and 446 multiparous) of 715 Holstein cows were obtained from 4 dairy herds located in Alberta, Canada, from 2014 to 2016. Cows had a mean $( \pm \mathrm{SD})$ milk yield of $38.0 \pm 9.0 \mathrm{~kg} / \mathrm{d}$ between 10 and 60 DIM. All herds used the IMAS as the primary reproductive management tool, in which AI were performed at spontaneous estrus determined based on milk $\mathrm{P} 4 \mathrm{c}$ profiles, as further described. Milk P4c measurement started at (mean $\pm \mathrm{SD}$ ) $24.5 \pm 8.2 \mathrm{DIM}$ and repeated at algorithm-driven intervals every $2.2 \pm 1.9 \mathrm{~d}$ until $173.4 \pm 49.3$ DIM, based on a biomodel described in detail by Friggens and Chagunda (2005). The IMAS biomodel used adjusted P4c values and a cut-off of 5.0 $\mathrm{ng} / \mathrm{mL}$ to identify onset and cessation of luteal phases based on proprietary calculations to identify variations in $\mathrm{P} 4 \mathrm{c}$ for each cow. A luteal phase was defined as the number of days of uninterrupted adjusted $\mathrm{P} 4 \mathrm{c}$ greater than or equal to $5.0 \mathrm{ng} / \mathrm{mL}$ until $\mathrm{P} 4 \mathrm{c}$ declined to less than $5.0 \mathrm{ng} / \mathrm{mL}$ (referred to as $\mathrm{P} 4 \mathrm{c}$ decline).

After the first luteal phase postpartum, the P4c decline was considered as the reference point for each $\mathrm{P} 4 \mathrm{c}$ profile to determine subsequent sampling frequency. The average sampling frequency at each stage of the $\mathrm{P} 4 \mathrm{c}$ profiles and demographics of herds evaluated here were reported in detail by Bruinjé et al. (2019). In brief, once a P4c decline was determined, estrus notification occurred in the IMAS software and AI was recommended to occur by 24 to $36 \mathrm{~h}$ (DeLaval International, 2011). After P4c decline, the sampling frequency was set by the biomodel to trigger the subsequent samples. Then, the first, second, third, and fourth subsequent samples occurred at (mean $\pm \mathrm{SD}$ ) $6.1 \pm 1.1,9.0 \pm 2.4$, $13.6 \pm 2.4$, and $16.8 \pm 2.1 \mathrm{~d}$ after $\mathrm{P} 4 \mathrm{c}$ decline, respectively (Bruinjé et al., 2019). The following samples were expected to occur daily between 18 and $25 \mathrm{~d}$, or until the next $\mathrm{P} 4 \mathrm{c}$ decline. If $\mathrm{P} 4 \mathrm{c}$ remained above the default cut-off $(5.0 \mathrm{ng} / \mathrm{mL})$ at d 25 , samples were automatically taken every second day until P4c dropped below 10.0 $\mathrm{ng} / \mathrm{mL}$, then samples were taken once or twice daily until the next $\mathrm{P} 4 \mathrm{c}$ decline. Once the subsequent $\mathrm{P} 4 \mathrm{c}$ decline occurred (e.g., if the cow was nonpregnant), the sampling frequency was recalculated for the next cycle.

When an AI event was recorded by $5 \mathrm{~d}$ after P4c decline, sampling frequency was standard until $25 \mathrm{~d}$, then repeated every 2 to $3 \mathrm{~d}$ between 25 and $30 \mathrm{~d}$. If P4c was still above the default cut-off at $30 \mathrm{~d}$, a PregN was issued by the system and the sampling frequency reduced to every $5 \mathrm{~d}$ until $55 \mathrm{~d}$ or until a $\mathrm{P} 4 \mathrm{c}$ decline, whichever occurred earlier (DeLaval International, 2011). In case of a true pregnancy where $\mathrm{P} 4 \mathrm{c}$ was expected to be continuously above the default cut-off, PregN were generated at every sampling event from 30 to $55 \mathrm{~d}$ after AI, when sampling automatically stopped (Figure 1). The IMAS software notified the end user whenever a change in status occurred (i.e., first PregN after AI or $\mathrm{P} 4 \mathrm{c}$ decline).

In the present data set, sets of filtering criteria were applied to the data as previously described (Bruinjé et al., 2019). The filtering criteria excluded lactations that had unexpected periods of no P4c measurements (i.e., gaps in sampling) and excluded $\mathrm{AI}$ events that did not occur based on the IMAS P4c profiles because of management decisions. Therefore, we used only AI records that had consistent IMAS data available before and after AI, and had subsequent confirmation of calving data available.

To validate the use of PregN generated by the IMAS to declare pregnancy and to determine the minimum interval after AI for which PregN will be most accurate, PregN at 4 weekly intervals were tested: at $30 \pm 3$ (27 to 33 ) d, at $37 \pm 3$ (34 to 40 ) d, at $44 \pm 3$ (41 to 47 ) d, and at $51 \pm 3$ (48 to 54 ) d after AI. Nonpregnancy was determined if no PregN was issued during each interval evaluated and a $\mathrm{P} 4 \mathrm{c}$ decline occurred by $55 \mathrm{~d}$ after AI. Based on the expected gestation duration (mean \pm 3 


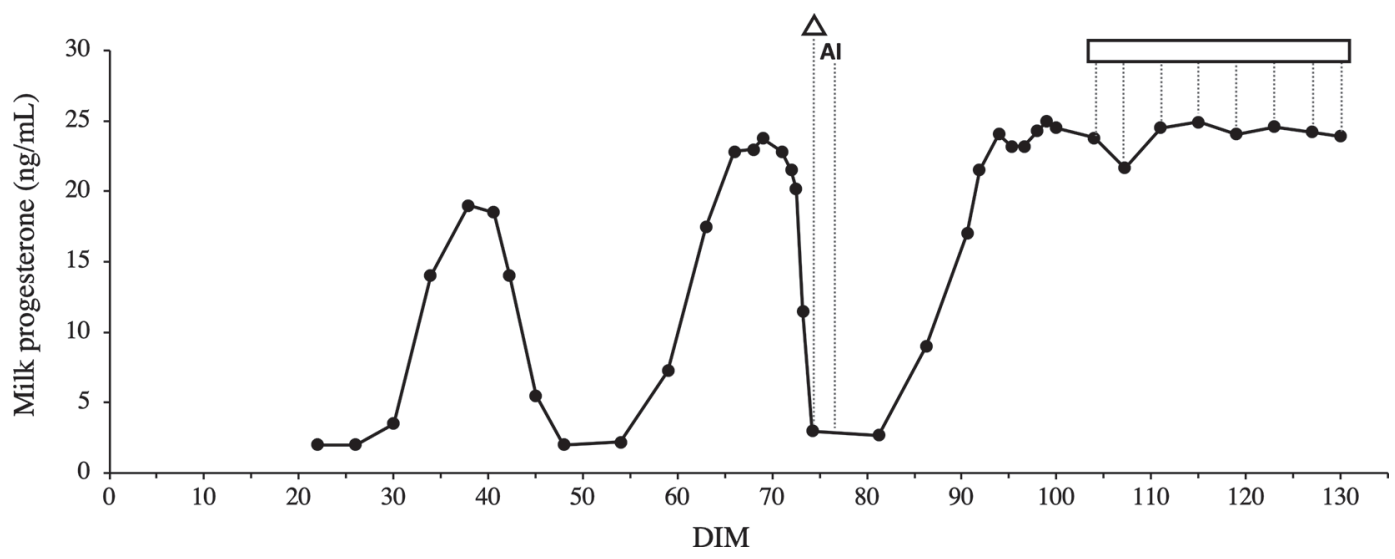

Figure 1. Postpartum milk progesterone profile obtained by an in-line milk analysis system (Herd Navigator, DeLaval International, Tumba, Sweden) of a hypothetical cow that, based on the standard cut-off of $5.0 \mathrm{ng} / \mathrm{mL}$ for luteal activity, the first luteal phase occurred between 34 and 48 DIM, the second luteal phase occurred between 59 and 74 DIM, a notification of estrus was generated at 74 DIM (open triangle), an AI was performed at 76 DIM, a new luteal phase initiated at 85 DIM, and pregnancy notifications (open rectangle) occurred between approximately 27 and $54 \mathrm{~d}$ after AI.

SD) for Holstein cows of $279 \pm 17 \mathrm{~d}$ (Norman et al., 2009), a confirmed calving that occurred between 262 and $296 \mathrm{~d}$ after AI, with no subsequent AI recorded, was the gold standard for confirming pregnancy status. To assess the precision of the IMAS in determining the day of P4c decline after AI, as an indication of imminent estrus in nonpregnant cows, the average sampling frequency during the last 3 samples before $\mathrm{P} 4 \mathrm{c}$ decline was evaluated.

Statistical procedures were performed with SAS 9.4 (Studio 3.71 platform, SAS Institute Inc., Cary, NC). The MEANS procedure was used to obtained descriptive statistics of herd demographics. Comparisons of sampling frequency among categories of interval from $\mathrm{AI}$ to subsequent $\mathrm{P} 4 \mathrm{c}$ decline were performed using the GLIMMIX procedure, including parity as a covariate and the random effect of herd. The occurrence of PregN at each of the 4 weekly intervals were binary variables $(0=$ nonpregnant or $1=$ pregnant $)$, as well as the confirmation of pregnancy based on the gold standard. The LOGISTIC procedure was used to obtain receiver operator characteristic (ROC) curves and the area under the curve, where PregN at each of the 4 weekly intervals was modeled against the gold standard. The FREQ procedure was used to obtain sensitivity [(true pregnant by IMAS) $/$ (gold standard pregnant) $\times 100]$, specificity [(true nonpregnant by IMAS)/(gold standard nonpregnant $) \times 100]$, positive predictive value [(true pregnant by IMAS)/(IMAS pregnant) $\times 100$, negative predictive value [(true nonpregnant by IMAS)/(IMAS nonpregnant $) \times 100]$, and accuracy [(true pregnant + true nonpregnant by IMAS) $/($ all AI evaluated $) \times 100$ ] for IMAS PregN assessed at each interval. Furthermore, Cohen's kappa statistics (Viera and Garrett, 2005) and
McNemar's tests were used to measure the agreement between PregN assessed at each weekly interval and the gold standard.

On average (mean \pm SD), AI occurred at $108.2 \pm$ 45.6 DIM. The number of postpartum AI at the time of pregnancy assessment averaged $2.1 \pm 1.4$. All AI occurred by $5 \mathrm{~d}$ after a $\mathrm{P} 4 \mathrm{c}$ decline notified as an estrus event by the IMAS, and the average sampling frequency of the last 3 samples before $\mathrm{P} 4 \mathrm{c}$ decline that preceded AI was $1.3 \pm 0.6$ samples per day. Milk P4c values at the time of $\mathrm{P} 4 \mathrm{c}$ decline (last sample preceding $\mathrm{AI}$ ) averaged $0.6 \pm 0.5 \mathrm{ng} / \mathrm{mL}$, and the interval between $\mathrm{P} 4 \mathrm{c}$ decline and $\mathrm{AI}$ was $1.8 \pm 0.6 \mathrm{~d}$. The first, second, and third samples after AI occurred at $4.6 \pm 0.6,10.0$ \pm 0.6 , and $14.1 \pm 0.6 \mathrm{~d}$ after $\mathrm{AI}$, respectively, with corresponding $\mathrm{P} 4 \mathrm{c}$ values of $3.1 \pm 4.3,16.2 \pm 7.0$, and $20.8 \pm 5.8 \mathrm{ng} / \mathrm{mL}$.

A majority $(53.2 \% ; 968 / 1,821)$ of AI events were not followed by an IMAS PregN, and 95.5\% (924/968) of these events was followed by a P4c decline and a new estrus alert generated by the IMAS by $30 \mathrm{~d}$ after AI. The mean $( \pm \mathrm{SD})$ interval between $\mathrm{AI}$ and $\mathrm{P} 4 \mathrm{c}$ decline, indicating imminent estrus and opportunity for reinsemination, was $21.7 \pm 3.1 \mathrm{~d}$ in the cycles $(\mathrm{n}=924)$ in which a P4c decline occurred by $30 \mathrm{~d}$ after AI. Of these, $57.7 \%$ (533/924), $22.8 \%$ (211/924), and $19.5 \%$ (180/924) had a P4c decline by $21 \mathrm{~d}$, between 22 and $23 \mathrm{~d}$, and beyond $24 \mathrm{~d}$ after AI, respectively (Figure 2a). Similarly, previous studies that evaluated $\mathrm{P} 4 \mathrm{c}$ profiles or luteal dynamics after AI in cows confirmed as nonpregnant at $32 \mathrm{~d}$ reported that $43.8 \%$ of cows had an extended luteal phase beyond $22 \mathrm{~d}$ after AI (Ricci et al., 2017), and $25 \%$ of cows retained their luteal structures up to $28 \mathrm{~d}$ after AI (Stevenson and Pulley, 2012). 
The distribution of the interval between $\mathrm{AI}$ and $\mathrm{P} 4 \mathrm{c}$ decline in cows that did not receive an IMAS PregN is presented in Figure 2a, which was similar to the distribution of over 114,000 inter-service intervals reported by Remnant et al. (2015). We observed only $1.9 \%$ (18/924) of nonpregnant cows with a P4c decline before $15 \mathrm{~d}$ after AI, which was similar to what was previously reported (Remnant et al., 2015; Ricci et al., 2017). The monitoring of the day of P4c decline after $\mathrm{AI}$ is a unique feature of the IMAS as it provides an opportunity for reinsemination as early as the spontaneous cessation of the luteal phase in nonpregnant cows, shortening the inter-service interval. In the present data set, the mean $( \pm \mathrm{SD})$ inter-service interval (i.e., interval between consecutive AI) in AI that were not followed by a PregN was $25.8 \pm 9.0 \mathrm{~d}$, and $25,50,75$, and $90 \%$ of the inter-service intervals were less than or equal to $22.0,23.0,26.0$, and $32.0 \mathrm{~d}$, respectively.

The IMAS biomodel reduces sampling frequency if $\mathrm{P} 4 \mathrm{c}$ remains high beyond $25 \mathrm{~d}$ after $\mathrm{P} 4 \mathrm{c}$ decline. Therefore, cows with extended luteal phases (e.g., P4c decline beyond $25 \mathrm{~d}$ after AI) could have the day of subsequent $\mathrm{P} 4 \mathrm{c}$ decline detected with reduced precision. The average sampling frequency of the last 3 samples before $\mathrm{P} 4 \mathrm{c}$ decline following $\mathrm{AI}$ of $1.3 \pm 0.6$ samples per day indicates a relatively high precision of the IMAS in detecting $\mathrm{P} 4 \mathrm{c}$ decline, as an indication of imminent estrus for reinsemination. In contrast, among AI events that were followed by a $\mathrm{P} 4 \mathrm{c}$ decline by $30 \mathrm{~d}$, the sampling frequency (mean $\pm \mathrm{SE}$ ) before $\mathrm{P} 4 \mathrm{c}$ decline was reduced $(P<0.001)$ when $\mathrm{P} 4 \mathrm{c}$ decline occurred either before $17 \mathrm{~d}$ or beyond $26 \mathrm{~d}$ after AI $(1.0 \pm 0.1$ samples per
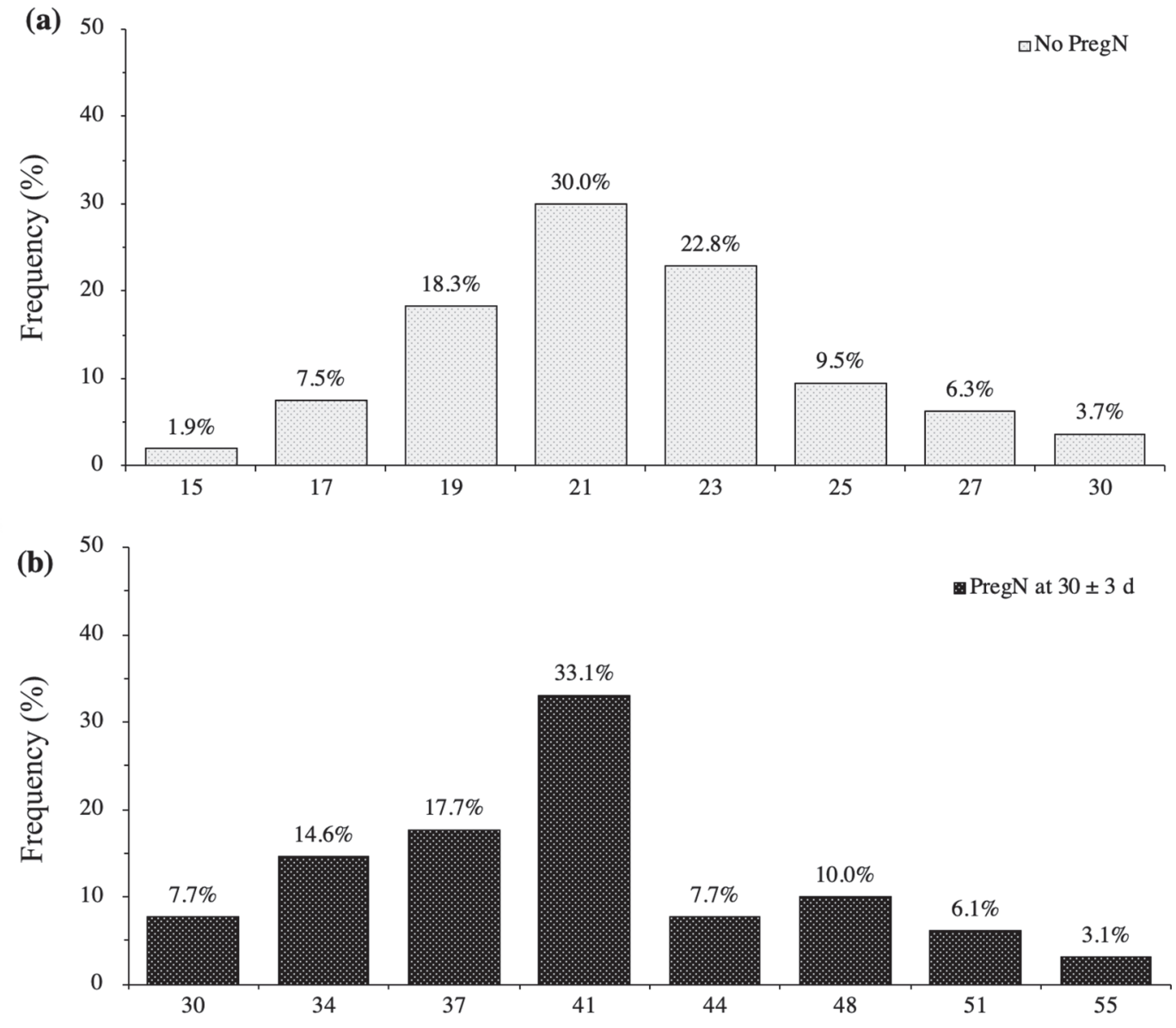

Interval between $\mathrm{AI}$ and $\mathrm{P} 4 \mathrm{c}$ decline (d)

Figure 2. Distribution of the interval between AI and decline in progesterone concentration (P4c decline) of subsequent luteal phase in (a) $924 \mathrm{AI}$ events that were not followed by a pregnancy notification (PregN) and had a P4c decline before $30 \mathrm{~d}$ after AI, and (b) 130 AI events of which the in-line milk analysis system (Herd Navigator, DeLaval International, Tumba, Sweden) PregN occurred at $30 \pm 3 \mathrm{~d}$ after AI and a subsequent P4c decline occurred by $55 \mathrm{~d}$ after AI, and no calving occurred between 262 and $296 \mathrm{~d}$ after AI. Among the latter, 40.0\% (52/130), $80.8 \%$ (105/130), and $96.9 \%$ (126/130) of the luteal phases after AI had a P4c decline by 37, 44, and 51 d after AI, respectively. 
day for both categories) compared with when P4c decline occurred between 18 and $25 \mathrm{~d}$ after AI $(1.4 \pm 0.1$ samples per day). As previously suggested (Bruinjé et al., 2019), continuing the greater frequency of sampling to beyond $25 \mathrm{~d}$ after AI should increase precision of estrus detection and reinsemination in cycles with an extended luteal phase.

Among AI events that were followed by an IMAS PregN, the interval (mean $\pm \mathrm{SD}$ ) between AI and first day of PregN was $30.6 \pm 2.8 \mathrm{~d}$. The overall proportions of AI events followed by a PregN at $30 \pm 3,37 \pm 3$, $44 \pm 3$, and $51 \pm 3 \mathrm{~d}$ were $46.8 \%(853 / 1,821), 45.3 \%$ (825/1,821), 42.7\% (778/1,821), and 40.9\% (744/1,821), respectively. Notably, 14 of the AI events that had a PregN at $51 \pm 3 \mathrm{~d}$ did not have a PregN at $30 \pm 3 \mathrm{~d}$ after AI, possibly due to delayed entry of the AI event, resulting in $730 \mathrm{AI}$ events with PregN both at $30 \pm 3$ and $51 \pm 3 \mathrm{~d}$ after AI.

Among those 123 AI events that had a PregN at 30 \pm 3 but not at $51 \pm 3 \mathrm{~d}$ after AI, 121 had P4c decline by $55 \mathrm{~d}, 1$ had $\mathrm{P} 4 \mathrm{c}$ decline at $57 \mathrm{~d}$, and 1 did not have a $\mathrm{P} 4 \mathrm{c}$ decline, with a calving recorded. In addition, 9 AI events had PregN both at $30 \pm 3$ and $51 \pm 3 \mathrm{~d}$, but also had a $\mathrm{P} 4 \mathrm{c}$ decline recorded by $55 \mathrm{~d}$ after AI. Therefore, $15.4 \%(130 / 853)$ AI events had a PregN at $30 \pm 3$ but were subsequently followed by a $\mathrm{P} 4 \mathrm{c}$ decline between 30 and $55 \mathrm{~d}$ (regardless of PregN at $51 \pm 3 \mathrm{~d}$ ) after AI, which occurred on average (mean $\pm \mathrm{SD}$ ) at $39.7 \pm 6.0$ $\mathrm{d}$ after AI. Of those, $40.0 \%$ (52/130), 80.8\% (105/130), and $96.9 \%(126 / 130)$ of $\mathrm{P} 4 \mathrm{c}$ decline events occurred by 37, 44, and $51 \mathrm{~d}$ after AI, respectively. The distribution of the interval between $\mathrm{AI}$ and subsequent $\mathrm{P} 4 \mathrm{c}$ decline in those $15.4 \%$ AI events that were followed by a PregN at $30 \pm 3 \mathrm{~d}$ but had a subsequent $\mathrm{P} 4 \mathrm{c}$ decline before 55 $\mathrm{d}$ after AI is presented in Figure 2b. A total of $40.7 \%$ $(742 / 1,821)$ of AI events was followed by a confirmed calving (i.e., gold standard). Of those, 3.1\% (23/742) was not previously followed by an IMAS PregN. The interval (mean $\pm \mathrm{SD}$ ) between $\mathrm{AI}$ and the last $\mathrm{P} 4 \mathrm{c}$ record measured in cows confirmed pregnant by the gold standard was $55.3 \pm 1.7 \mathrm{~d}$.

The $15.4 \%$ of AI events that had an IMAS PregN at $30 \pm 3$ but were later followed by a $\mathrm{P} 4 \mathrm{c}$ decline by $55 \mathrm{~d}$ may have resulted from either embryonic losses during that period (Santos et al., 2004), prolonged luteal phases (Ricci et al., 2017), or both. For instance, approximately $12.8 \%$ of pregnancy losses occur from 27-31 to 38-50 d after AI in lactating dairy cows (Santos et al., 2004). Though based exclusively on the IMAS PregN and $\mathrm{P} 4 \mathrm{c}$ decline events, our findings indicate a similar prevalence $(15.4 \%$; 130/853) of pregnancy losses between approximately 30 and $55 \mathrm{~d}$ after AI. Furthermore, $3.4 \%(25 / 744)$ of AI events that had a PregN at $51 \pm 3 \mathrm{~d}$ were not followed by a confirmed calving, indicating a relatively small proportion of late pregnancy losses.

The high prevalence of extended luteal phases might be a limitation of diagnosing pregnancy too early based on $\mathrm{P} 4 \mathrm{c}$ profiles alone. If the retention of luteal structures extends beyond when an early pregnancy loss (e.g., at $30 \mathrm{~d}$ after AI) occurs, it could result in elevated $\mathrm{P} 4 \mathrm{c}$ resulting in false PregN at $30 \pm 3 \mathrm{~d}$ after AI. In this regard, Stevenson and Pulley (2012) reported that $19.4 \%$ of nonpregnant cows that had retained luteal structures until $28 \mathrm{~d}$ after AI had elevated pregnancyspecific protein B at d 32. Furthermore, Ricci et al. (2017) reported that 41 and $58 \%$ of nonpregnant cows with extended luteal phases beyond $32 \mathrm{~d}$ after AI had pregnancy-associated glycoprotein levels indicative of pregnancy at 25 and at $32 \mathrm{~d}$, respectively. These findings indicate that $\mathrm{P} 4 \mathrm{c}$ can stay elevated for at least up to $7 \mathrm{~d}$ after an early pregnancy loss occurs.

The area under the curve (and 95\% CI) for diagnosing pregnancy based on IMAS PregN at $30 \pm 3 \mathrm{~d}, 37 \pm$ $3,44 \pm 3$, and at $51 \pm 3 \mathrm{~d}$ after AI were 0.91 (CI 0.90 to 0.92 ), 0.93 (CI 0.91 to 0.94 ), 0.95 (CI 0.95 to 0.96 ), and 0.97 (CI 0.97 to 0.98), respectively (Figure $3 ; P<$ $0.001)$. For all intervals tested, sensitivity values were greater than $95.0 \%$, indicating a very high ability for the IMAS PregN at any time point to correctly identify pregnant cows. Specificity values were below $90.0 \%$ for PregN at $30 \pm 3$ and at $37 \pm 3 \mathrm{~d}$ after AI, $94.4 \%$ for PregN at $44 \pm 3$, and $97.7 \%$ for PregN at $51 \pm 3$ $\mathrm{d}$ after AI, indicating a very high precision $(\sim 95.0 \%)$ of the IMAS in correctly identifying nonpregnant cows beyond $41 \mathrm{~d}$ after AI. The accuracy of the IMAS PregN in correctly diagnosing pregnancy or nonpregnancy was high $(>90.0 \%)$ between 27 and $40 \mathrm{~d}$ after AI, and very high $(>95.0 \%)$ when assessed beyond $41 \mathrm{~d}$ after AI. The level of agreement between PregN and the gold standard was high $(k \geq 0.80)$ for PregN assessed at all intervals. The positive and negative predictive values, sensitivity, specificity, accuracy, and Cohen's kappa statistics values for diagnosing pregnancy based on IMAS PregN at each weekly interval are presented in Table 1. McNemar's test revealed that proportions of the outcomes (i.e., sensitivity and specificity values) in the $2 \times 2$ contingency tables among all tests were different $(P<0.001)$. However, the proportion of pregnancy and nonpregnancy as determined by PregN of IMAS at $51 \pm 3$ versus the gold standard did not differ $(P=$ 0.77 ), indicating accordance between the proportion of pregnancies determined by the IMAS beyond $48 \mathrm{~d}$ and the gold standard.

According to a simulation model, for an early chemical pregnancy test (at $31 \mathrm{~d}$ after $\mathrm{AI}$ ) to be economically comparable with pregnancy diagnosis by palpation per rectum at $39 \mathrm{~d}$ after $\mathrm{AI}$, it had to have sensitiv- 


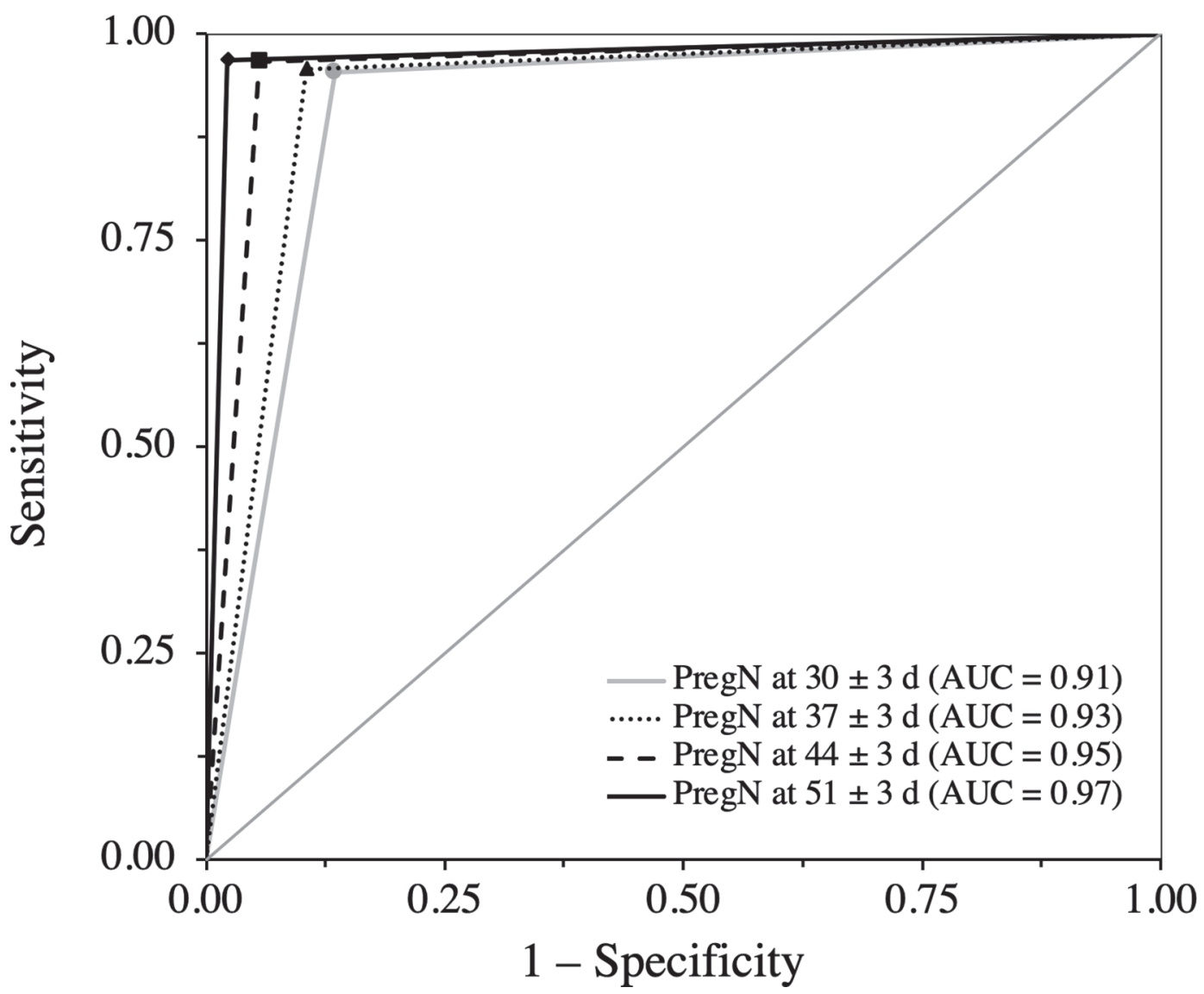

Figure 3. Receiver operating characteristic (ROC) curves for pregnancy notifications (PregN) generated by an in-line milk analysis system (Herd Navigator, DeLaval International, Tumba, Sweden) assessed at different intervals after AI: at $30 \pm 3$ d, resulting in an area under the curve (AUC) of 0.91 (95\% CI 0.90 to $0.92 ; P<0.001$ ); at $37 \pm 3 \mathrm{~d}$, resulting in an AUC of 0.93 (95\% CI 0.91 to $0.94 ; P<0.001$ ); at $44 \pm 3 \mathrm{~d}$, resulting in an AUC of 0.95 (95\% CI 0.95 to $0.96 ; P<0.001$ ); and at $51 \pm 3 \mathrm{~d}$, resulting in an AUC of 0.97 (95\% CI 0.97 to $0.98 ; P<0.001$ ). Confirmation of calving that occurred between 262 and $296 \mathrm{~d}$ after AI was considered the gold standard for pregnancy.

ity and specificity values of at least 96.4 and $95.1 \%$, respectively (Giordano et al., 2013). Based on that, the assessment of IMAS PregN before $40 \mathrm{~d}$ after AI had sub-optimal specificity values $(<90.0 \%)$. However, it is important to note that direct comparisons between the IMAS for pregnancy determination and a chemical pregnancy test performed at a fixed day, such as pregnancy-associated glycoprotein, or transrectal palpation, might not be appropriate. In contrast to other pregnancy diagnosis methods, the IMAS is dynamic in

Table 1. Positive (PPV) and negative (NPV) predictive values, sensitivity (Se), specificity (Sp), accuracy, and Cohen's kappa statistics ( $k$ ) for inter-test agreement of $\mathrm{IMAS}^{1}$ pregnancy notification (PregN) assessed at different intervals after AI in 1,821 AI events

\begin{tabular}{lcccrrr}
\hline Days after AI (interval) & PPV $(\%)$ & NPV $(\%)$ & Se $(\%)$ & Sp $(\%)$ & Accuracy $(\%)$ & $k(95 \%$ CI $)$ \\
\hline $30(27$ to 33$)$ d & 82.88 & 96.38 & 95.28 & 86.47 & $90.06^{\mathrm{a}}$ & $0.80(0.77$ to 0.83$)$ \\
37 (34 to 40$)$ d & 86.18 & 96.89 & 95.82 & 89.43 & $92.04^{\mathrm{b}}$ & $0.84(0.81$ to 0.86$)$ \\
$44(41$ to 47$)$ d & 92.16 & 97.60 & 96.63 & 94.35 & $95.28^{\mathrm{c}}$ & $0.90(0.88$ to 0.92$)$ \\
51 (48 to 54$)$ d & 96.64 & 97.86 & 96.90 & 97.68 & $97.36^{\mathrm{d}, \mathrm{x}}$ & $0.95(0.93$ to 0.96$)$ \\
\hline
\end{tabular}

${ }^{\mathrm{a}-\mathrm{d}} \mathrm{McNemar}$ 's test revealed that the proportions of sensitivities and specificities between tests were different $(P<0.001)$.

${ }^{\mathrm{x}}$ The proportion of pregnancy as determined by PregN at $51 \pm 3 \mathrm{~d}(40.9 \%)$ and the gold standard $(40.7 \%)$ did not differ $(P=0.77)$.

${ }^{1}$ In-line milk analysis system (Herd Navigator, DeLaval International, Tumba, Sweden).

${ }^{2}$ Categories of different intervals between AI and assessment of the IMAS pregnancy notification. The proportion of AI events followed by PregN at 30 (27 to 33 ), 37 (34 to 40$), 44$ (41 to 47 ), and 51 (48 to 54$)$ d were $46.8 \%$ (853/1,821), $45.3 \%(825 / 1,821), 42.7 \%(778 / 1,821)$, and $40.9 \%$ $(744 / 1,821)$, respectively. In all, $40.7 \%(742 / 1,821)$ of AI were confirmed pregnant by the gold standard (i.e., calving occurring between 262 and 296 d after AI). 
identifying nonpregnant cows on a real-time-basis by monitoring the spontaneous cessation of luteal phase after AI, which indicates an imminent estrus and opportunity for an early reinsemination.

In conclusion, pregnancy notifications generated by the IMAS had high sensitivity $(>95.0 \%)$ when assessed at any time point, starting at $27 \mathrm{~d}$ after AI. Specificity values were less than $90.0 \%$ for pregnancy notifications before $40 \mathrm{~d}$ after AI, likely resulting from the early pregnancy losses, extended luteal phases, or both. From $41 \mathrm{~d}$ after AI, the IMAS was a highly accurate (>95.0\%) diagnostic tool for automated determination of pregnancy status. Besides, the system is capable of identifying nonpregnant cows as soon as spontaneous cessation of the luteal phase occurs after AI. However, increasing the period of high sampling frequency beyond the expected luteal phase length might improve precision of reinsemination in cows with an extended luteal phase after AI.

\section{ACKNOWLEDGMENTS}

This study was supported by Alberta Milk and the Strategic Research and Development Program, Alberta Agriculture and Forestry (Agriculture Funding Consortium Grant \#2016F056R, Canada). The authors thank DeLaval Canada (Peterborough, ON, Canada) and Lattec I/S (Hillerød, Denmark) for their technical support with the data collection and the owners of the commercial dairy farms involved in the study for their cooperation.

\section{REFERENCES}

Bruinjé, T. C., M. G. Colazo, E. S. Ribeiro, M. Gobikrushanth, and D. J. Ambrose. 2019. Using in-line milk progesterone data to characterize parameters of luteal activity and their association with fertility in Holstein cows. J. Dairy Sci. 102:780-798. https://doi .org/10.3168/jds.2018-14654.

DeLaval International. 2011. Herd Navigator ${ }^{\mathrm{TM}}$ and reproduction management. Accessed Jul. 8, 2015. http://delaval-com-www .gtm.episerverhosting.com/PageFiles/171203/53571175_HN _Reproduktion managementLOWRES.pdf.

Fricke, P. M., A. Ricci, J. O. Giordano, and P. D. Carvalho. 2016. Methods for and implementation of pregnancy diagnosis in dairy cows. Vet. Clin. North Am. Food Anim. Pract. 32:165-180. https: //doi.org/10.1016/j.cvfa.2015.09.006.
Friggens, N. C., and M. G. G. Chagunda. 2005. Prediction of the reproductive status of cattle on the basis of milk progesterone measures: Model description. Theriogenology 64:155-190. https:// doi.org/10.1016/j.theriogenology.2004.11.014.

Giordano, J. O., P. M. Fricke, and V. E. Cabrera. 2013. Economics of resynchronization strategies including chemical tests to identify nonpregnant cows. J. Dairy Sci. 96:949-961. https://doi.org/10 $.3168 /$ jds.2012-5704.

Mayo, L. M., S. G. Moore, S. E. Poock, W. J. Silvia, and M. C. Lucy. 2016. Technical note: Validation of a chemical pregnancy test in dairy cows that uses whole blood, shortened incubation times, and visual readout. J. Dairy Sci. 99:7634-7641. https://doi.org/ $10.3168 /$ jds.2016-11224.

Norman, H. D., J. R. Wright, M. T. Kuhn, S. M. Hubbard, J. B. Cole, and P. M. VanRaden. 2009. Genetic and environmental factors that affect gestation length in dairy cattle. J. Dairy Sci. 92:22592269. https://doi.org/10.3168/jds.2007-0982.

Remnant, J. G., M. J. Green, J. N. Huxley, and C. D. Hudson. 2015. Variation in the interservice intervals of dairy cows in the United Kingdom. J. Dairy Sci. 98:889-897. https://doi.org/10.3168/jds .2014-8366.

Ricci, A., P. D. Carvalho, M. C. Amundson, and P. M. Fricke. 2017. Characterization of luteal dynamics in lactating Holstein cows for 32 days after synchronization of ovulation and timed artificial insemination. J. Dairy Sci. 100:9851-9860. https://doi.org/10.3168/ jds.2017-13293.

Romano, J. E., J. A. Thompson, D. W. Forrest, M. E. Westhusin, M. A. Tomaszweski, and D. C. Kraemer. 2006. Early pregnancy diagnosis by transrectal ultrasonography in dairy cattle. Theriogenology 66:1034-1041. https://doi.org/10.1016/j.theriogenology .2006.02.044.

Saint-Dizier, M., and S. Chastant-Maillard. 2012. Towards an automated detection of oestrus in dairy cattle. Reprod. Domest. Anim. 47:1056-1061. https://doi.org/10.1111/j.1439-0531.2011.01971.x.

Santos, J. E. P., W. W. Thatcher, R. C. Chebel, R. L. A. Cerri, and K. N. Galvão. 2004. The effect of embryonic death rates in cattle on the efficacy of estrus synchronization programs. Anim. Reprod. Sci. 82-83:513-535. https://doi.org/10.1016/j.anireprosci.2004.04 .015 .

Siqueira, L. G. B., V. S. Areas, A. M. Ghetti, J. F. Fonseca, M. P. Palhao, C. A. C. Fernandes, and J. H. M. Viana. 2013. Color Doppler flow imaging for the early detection of nonpregnant cattle at 20 days after timed artificial insemination. J. Dairy Sci. 96:64616472. https://doi.org/10.3168/jds.2013-6814.

Stevenson, J. S., and S. L. Pulley. 2012. Characteristics and retention of luteal structures, extended postinsemination cycle, progesterone, and pregnancy-specific protein B in serum after human chorionic gonadotropin treatment of dairy cows. J. Dairy Sci. 95:4396-4409. https://doi.org/10.3168/jds.2011-5286.

Viera, A. J., and J. M. Garrett. 2005. Understanding interobserver agreement: The Kappa statistic. Fam. Med. 37:360-363.

Wilsdorf, L. J., D. H. Keisler, S. E. Poock, W. R. Lamberson, R. C. Escalante, and M. C. Lucy. 2016. Short communication: Test for nonpregnancy in dairy cows based on plasma progesterone concentrations before and after timed artificial insemination. J. Dairy Sci. 99:5858-5865. https://doi.org/10.3168/jds.2016-10864. 